\title{
NIEVERGELT-PEARLMAN SYNDROME WITH IMPAIRMENT OF HEARING
}

\author{
REPORT OF THREE CASES IN A FAMILY
}

Yukitomo Murakami, Imabari, Japan

Three cases of the Nievergelt-Pearlman syndrome occurring in a family are presented. In addition to the major features of the syndrome (symphalangism, carpal fusion, atypical club foot with massive tarsal fusion, and congenital dislocation of the head of the radius), all three patients exhibited conductive deafness, which had not been recorded in previous reports. The clinical findings strongly suggested that the loss of hearing was due to fusion of the ossicles of the middle ear.

In 1944 Nievergelt described a man and his three sons with rare abnormalities of the upper and lower limbs-dysplasia of the elbow with radio-ulnar synostosis which they termed the Nievergelt syndrome. The patients described by Pearlman and his colleagues, however, did not have dysplasia of the tibia but had symphalangism

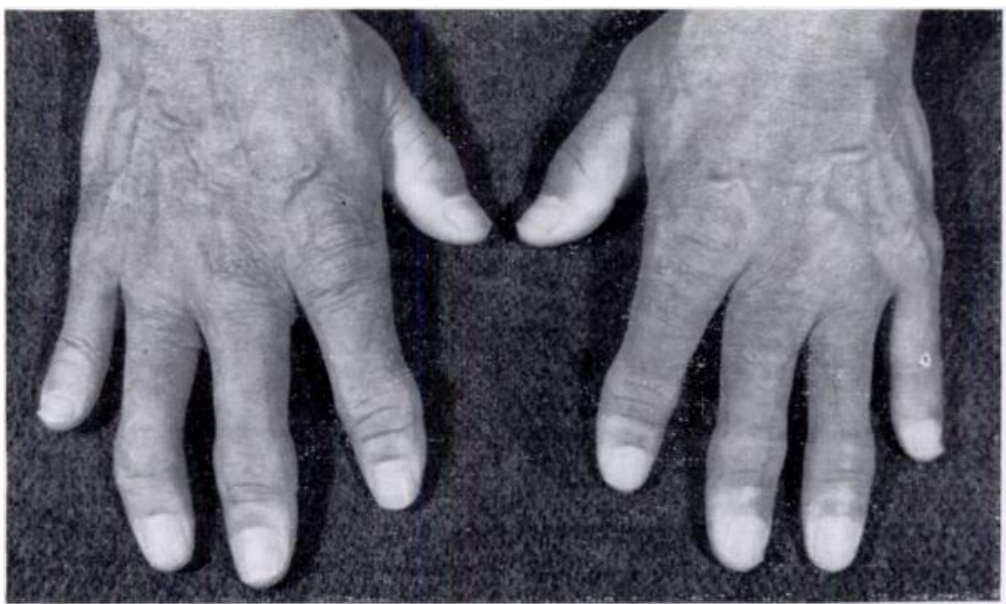

FIG. 1

Case 1-A photograph of the hands showing the short digits, the atsence of cutaneous folds over the involved interphalangeal joints, and clinodactyly of the right ring finger.

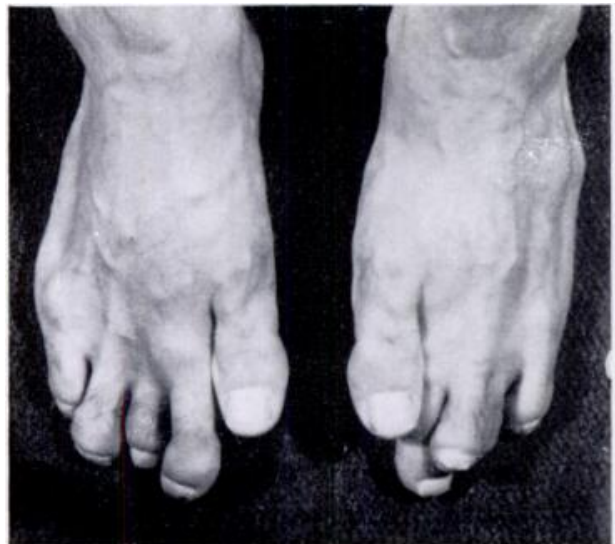

Fig. 2

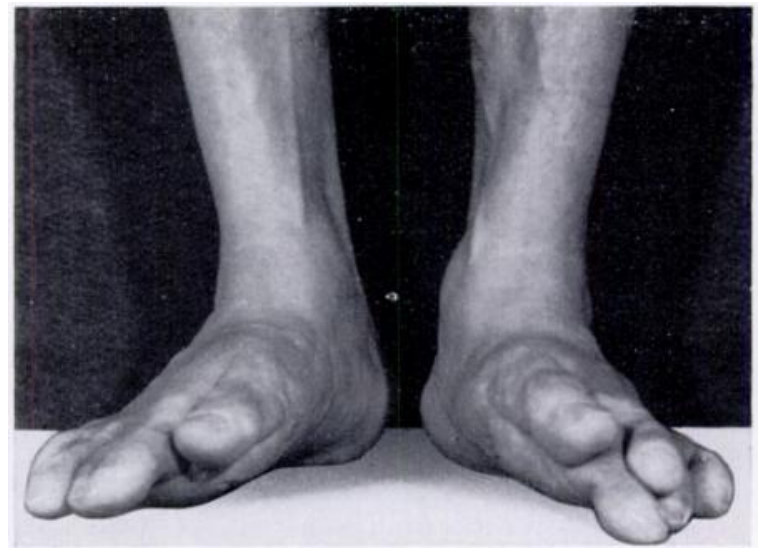

FIG. 3

Case 1-Photographs of the feet, showing the short great toes and the inability to take weight on the first metatarsal.

and subluxation of the radius or ulna, dysplasia of the tibia and fibula, and atypical club foot with tarsal fusion. Solonen and Sulamaa (1958) and Pearlman, Edkin and Warren (1964) added patients with similar abnormalities and carpal fusion, which were not mentioned in Nievergelt's report. In 1970 Dubois reported a girl with abnormalities which resembled those of Pearlman and his colleagues and which he named the Nievergelt-Pearlman 
syndrome. A search of the literature reveals very few reports of similar cases (Sano, Sakuma, Nakano and Kurihara 1964; Shin, Ikuta, Hieda and Ikari 1965; Hasebe and Okochi 1972; Yasue, Fujii, Kumon and Sakabe 1973).

This paper reports three additional cases of the
Since early childhood he had noticed stiffness of the fingers and difficulty in hearing. He complained of pain in the feet on standing for long periods and had difficulty in walking long distances. The abnormalities did not occur in his son, six siblings or parents, but affected only him and his daughters (Cases 2 and 3). His parents were not consanguineous.

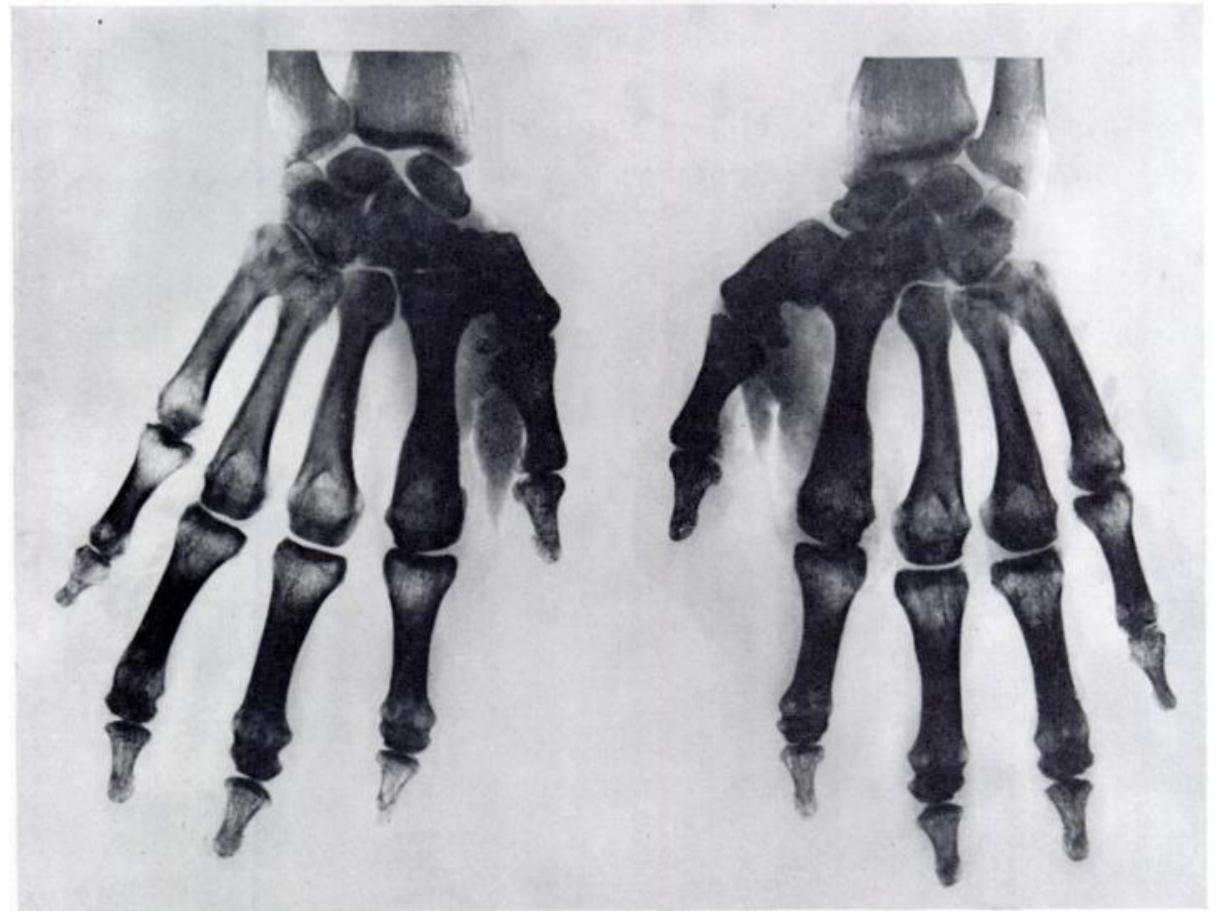

Fig. 4

Case 1-A radiograph of the hands showing various carpal fusions, marked shortening of the first metacarpals, and a single joint in each of the fingers.
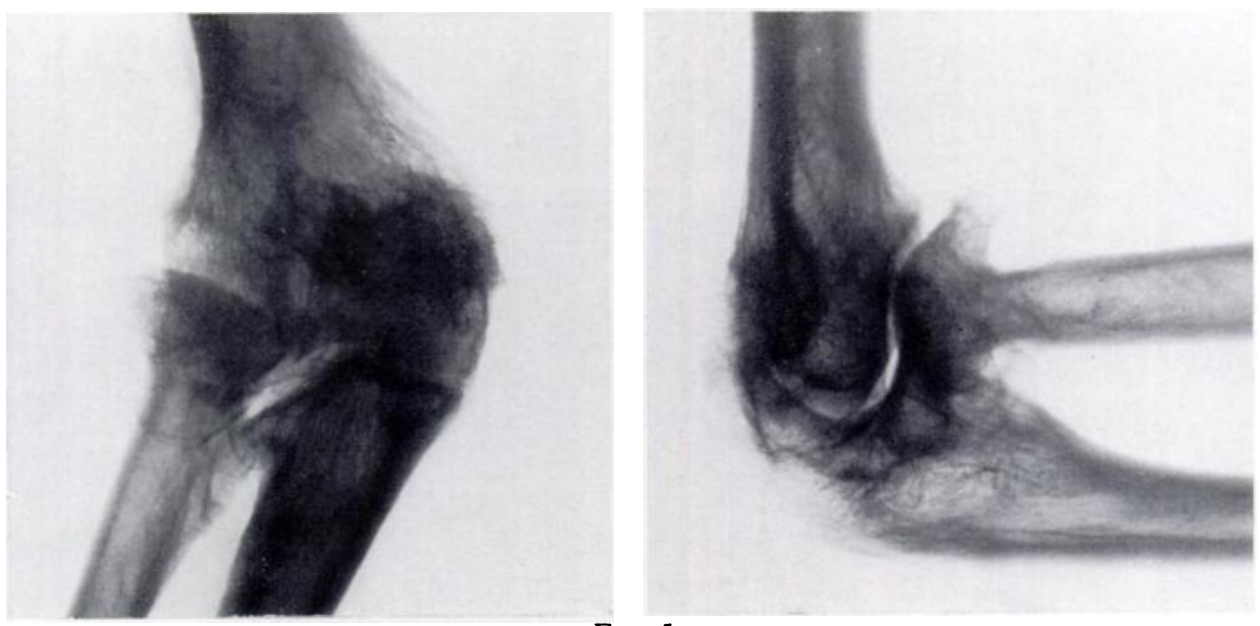

FIG. 5

Case 1-Radiographs of the right elbow showing anterior dislocation of the head of the radius and marked osteoarthritic changes.

Nievergelt-Pearlman syndrome occurring in a family, but with impairment of hearing as an associated abnormality. This has not been recorded in previous papers.

\section{CASE REPORTS}

Case 1-A Japanese farmer aged forty-eight was admitted to hospital with an injury of the neck sustained in a fall from a height. Various abnormalities of the elbows, hands and feet were discovered on physical and radiographic examination.
On examination he was a well-developed man 165 centimetres in height. He had difficulty in hearing ordinary speech, but the tympanic membranes were normal macroscopically. The fingers were short and there appeared to be only two phalanges in each (Fig. 1). The skin overlying the affected joints was smooth and lacked the normal fold produced by flexion, which was absent. Movement of the unaffected joints was good. The right ring finger showed some radial deviation at the distal joint (clinodactyly). There was no limitation of wrist movement. Both elbows showed a flexion deformity, 
with a range of movement from 55 to 155 degrees on the left and from 70 to 145 degrees on the right. Both great toes were short (Fig. 2), and both feet showed a varus deformity (Fig. 3), causing him to walk unsteadily on the outer borders.

Radiographs of the hands (Fig. 4) showed fusion of the proximal interphalangeal joints of the index, middle and ring fingers and fusion of the distal interphalangeal joint of the the feet revealed fusion of the distal joints of the lesser toes (Figs. 6 and 7). The first metatarsal was short and fused with the medial cuneiform. The third metatarsal appeared smaller and shorter than usual. There was also multiple fusion of the tarso-metatarsal and intermetatarsal joints. All the tarsal bones except the medial cuneiform were fused into one bone. A skeletal survey disclosed a typical "ball and socket" ankle

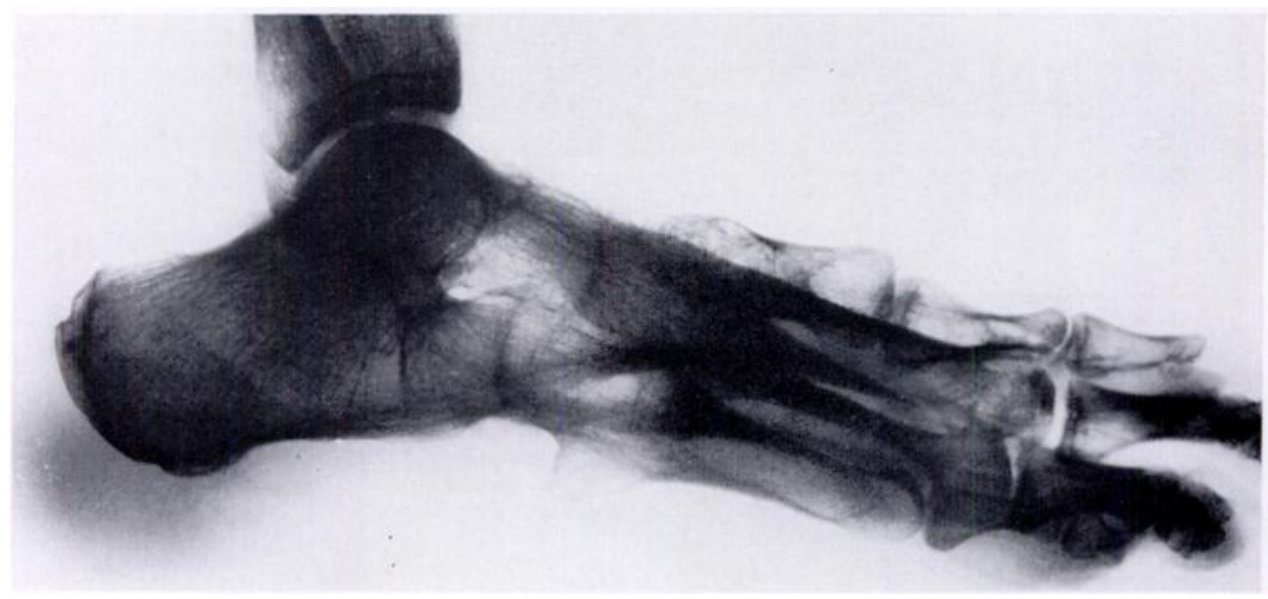

FIG. 6

Case 1-A lateral radiograph of the right foot showing the massive tarsal fusion.

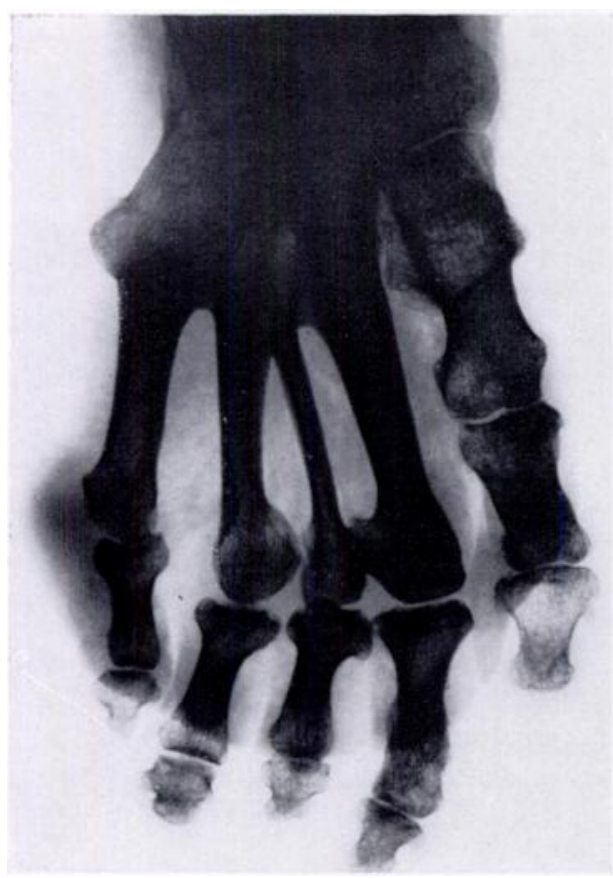

FIG. 7

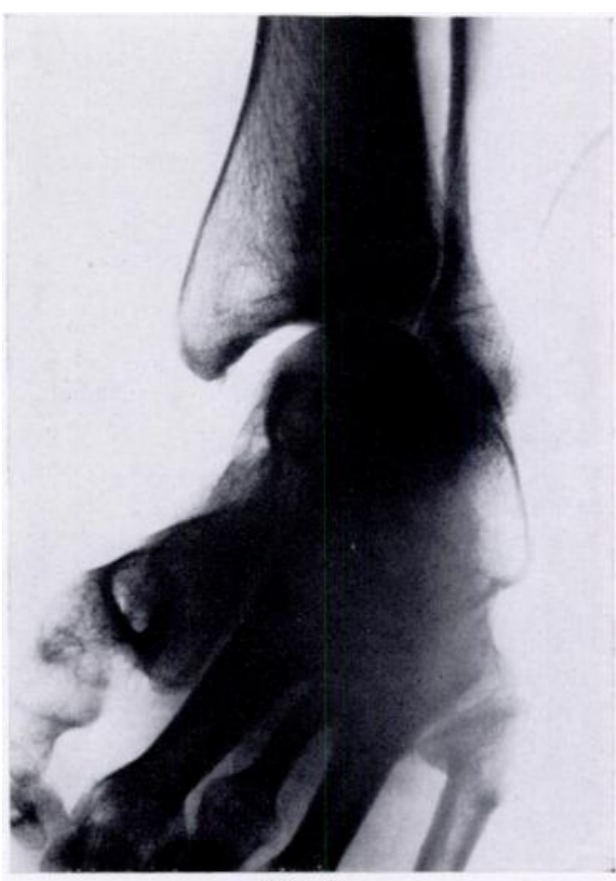

FIG. 8

Case 1. Figure 7-An antero-posterior radiograph of the right foot showing the short first ray and fusion of tarso-metatarsal and intermetatarsal joints. Figure 8-A radiograph of the right ankle showing a typical "ball and socket" joint.

little finger. The middle phalanx of each affected finger was extremely short. The joint vestige was more obvious in the index and middle fingers than in the little finger. The first metacarpal was very short and was fused with the trapezium; the heads of the second, third and fourth metacarpals were flattened. On the left side there was fusion of second metacarpal, trapezoid and capitate, and of hamate and triquetrum. On the right side there was also fusion of trapezoid and capitate and of hamate and triquetrum. Radiographs of the elbows showed anterior dislocation of the head of the radius and marked osteoarthritic changes (Fig. 5). Radiographs of
(Fig. 8) and fusion between the first and second dorsal vertebrae.

The audiogram revealed a hearing loss by air conduction of 60 to 70 decibels between frequencies of 512 to 2,048 on the left, and of 65 to 70 decibels between the same frequencies on the right. Bone conduction was normal on both sides. The results of laboratory studies including a complete blood count, urinalysis, blood chemistry and liver function test were within normal limits.

Case 2-The elder daughter, aged fifteen, was found to have similar abnormalities. Stiffness of the fingers was first noted 
at the age of one year. She had had impaired hearing since early childhood and had been troubled by painful feet for several years.

On examination she was a well-nourished healthy girl 156 centimetres in height. The tympanic membranes were clear and not scarred. Both hands had short digits with only one interphalangeal joint in each finger. There was slight radial deviation at the distal joint of both ring fingers. Inability to flex the involved phalangeal joints resulted in a weak grip. The function of the wrists was normal. Both elbows showed valgus of 25 degrees but normal movement. Both feet showed a varus deformity and she walked unsteadily. Movement of the ankles was normal but the subtalar joints were fixed. on both sides but normal movement. The feet showed varus deformity and she walked with a shuffling gait.

Radiographs of the hands showed fusion of both joints of the index fingers and of the proximal joint of the middle and ring fingers (Fig. 11). The little finger showed absence of the middle phalanx. The first metacarpal showed extreme shortening and was fused with the trapezium. The bases of the right fourth and fifth metacarpals were fused. The trapezoid, capitate and triquetrum were fused. Radiographs of the elbows revealed anterior dislocation of the head of the radius. Radiographs of the feet showed distal interphalangeal fusion of all the lesser toes except the left second toe. The short first metatarsals were fused with the medial cuneiforms. All the tarsal bones except the medial cuneiform

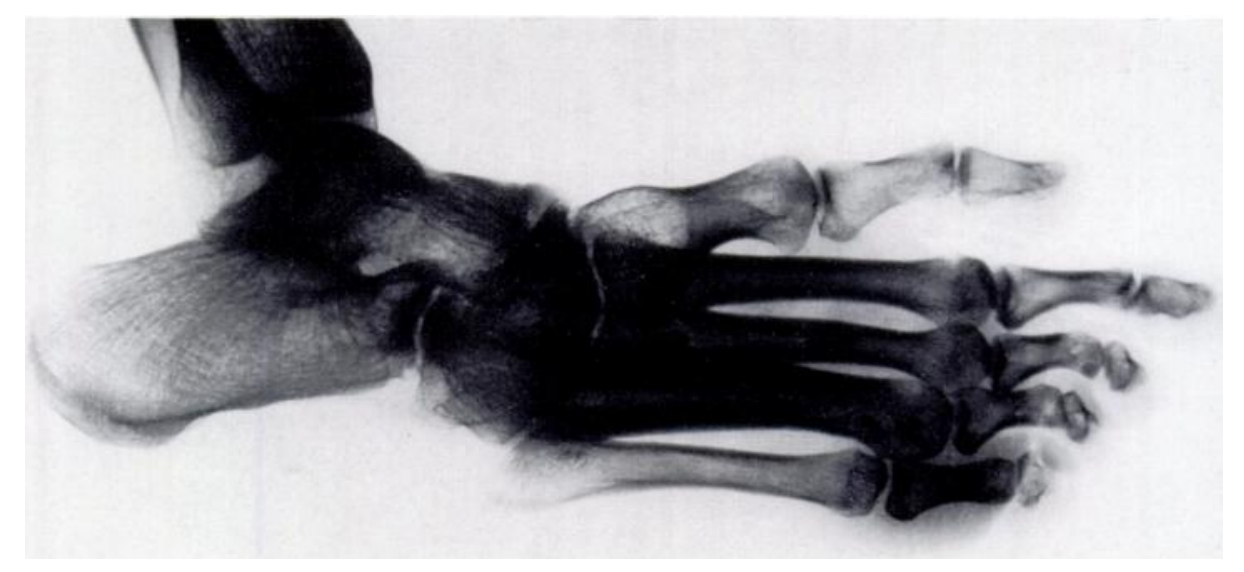

Fig. 9

Case 2-A lateral radiograph of the right foot showing absence of the middle phalanges of the lesser toes and extensive tarsal fusion.

Radiographs of the hands revealed fusion of the proximal interphalangeal joints of the index, middle and ring fingers. The middle phalanx of the little finger was absent. The first metacarpal was short and fused with the trapezium. There was fusion between trapezoid and capitate and also between hamate and triquetrum. Radiographs of the elbows showed valgus deformity and anterior dislocation of the head of the radius. Radiographs of the feet revealed fusion of the distal joints of the lesser toes (Fig. 9). The short first metatarsals were fused with the medial cuneiforms. On the left side all the tarsal bones except the medial cuneiform were fused into a bony mass. The bases of the second, third, fourth and fifth metatarsal bones were fused together and with the tarsal mass. On the right side there was fusion of the fourth metatarsal, cuboid, intermediate and lateral cuneiforms, and also of navicular, talus and calcaneus.

Audiograms showed a hearing loss by air conduction of 50 to 65 decibels between frequencies of 512 to 2,048 on the left, and of 55 to 60 decibels between these frequencies on the right. Bone conduction was normal in both ears.

Case 3-The younger daughter, aged fourteen, gave a similar history. She had been troubled with stiffness of the fingers and painful feet for many years. She had worn a hearing aid since childhood.

On examination she had an average physique and was 141 centimetres in height. The tympanic membranes were normal. Both index fingers were stiff in extension (Fig. 10). The middle, ring and little fingers had only one interphalangeal joint. The right little finger was short and was held in abduction. The left ring finger showed clinodactyly. She was unable to pinch an object between thumb and index. Movement of both wrists was full. There was mild cubitus valgus were fused into a single mass (Fig. 12). The bases of the second, third, fourth and fifth metatarsals were fused between themselves and with the single tarsal bone.

Audiograms revealed a significant hearing loss by air conduction of 70 to 90 decibels between frequencies of 512 and 2,048 on the left and of 40 to 80 decibels between these frequencies on the right. Bone conduction was normal.

\section{DISCUSSION}

The Nievergelt-Pearlman syndrome is a rare hereditary condition. Only ten cases have previously been described in the world literature (Table I). The syndrome consists of: 1) symphalangism; 2) carpal fusion; 3) atypical club feet with tarsal fusion; and 4) dysplasia of the elbows with dislocation or subluxation of the head of the radius. Humero-radial or humero-ulnar synostosis, brachydactyly and clinodactyly have been described as additional abnormalities. The cases of Nievergelt himself and of Solonen and Salamaa are somewhat different from the cases listed in Table I; symphalangism and carpal fusion were absent.

Symphalangism of the fingers is usually found, the site of predilection being the proximal interphalangeal joints. The thumb is rarely affected. Inability to flex the involved joints usually results in a weak grip. Nevertheless, the patients feel no inconvenience in daily use 
because of compensation by the other joints. In the toes symphalangism occurs as a rule in the distal interphalangeal joints, an abnormality often seen in the fifth toes of otherwise normal subjects.

Carpal and tarsal fusions are also main features of this syndrome. The bones of the distal row of the carpus reduced movement of the subtalar and tarso-metatarsal joints. The feet often show varus deformity with the first metatarsal not bearing weight. The patient walks unsteadily on the outer borders of the feet and usually gives a history of pain on prolonged standing or walking. The feet cause the patient much more inconvenience than

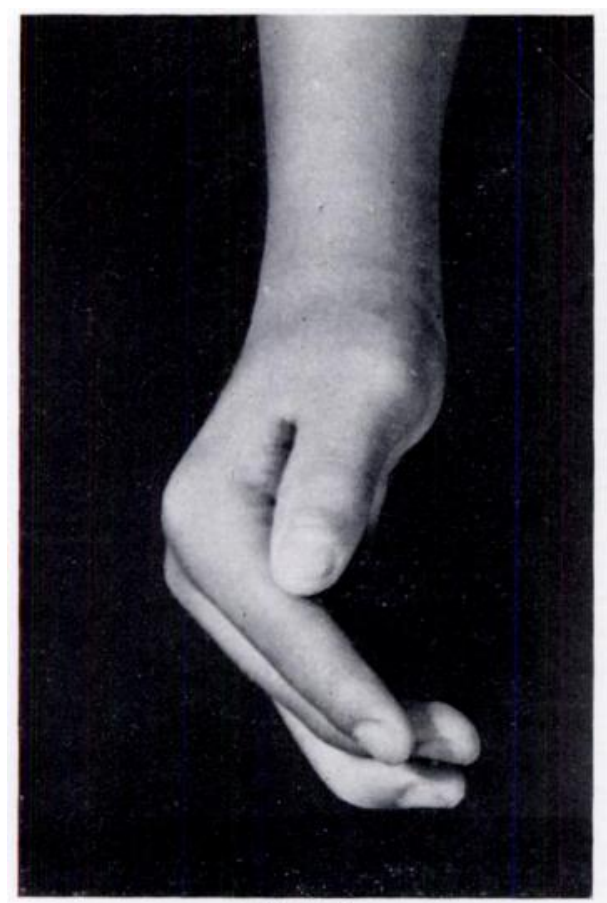

FIG. 10

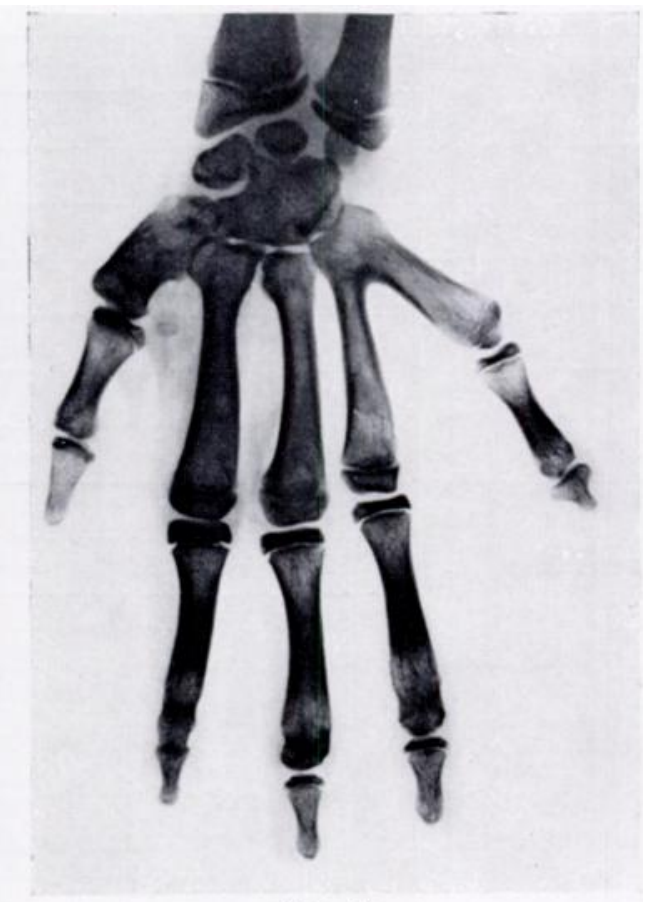

FIG. 11

Case 3. Figure 10-A photograph of the right hand showing the straight index and the inability to pinch. Figure 11-A radiograph of the right hand. Note the fusion of the interphalangeal joints of the index, and also fusion between the bases of the fourth and fifth metacarpals.

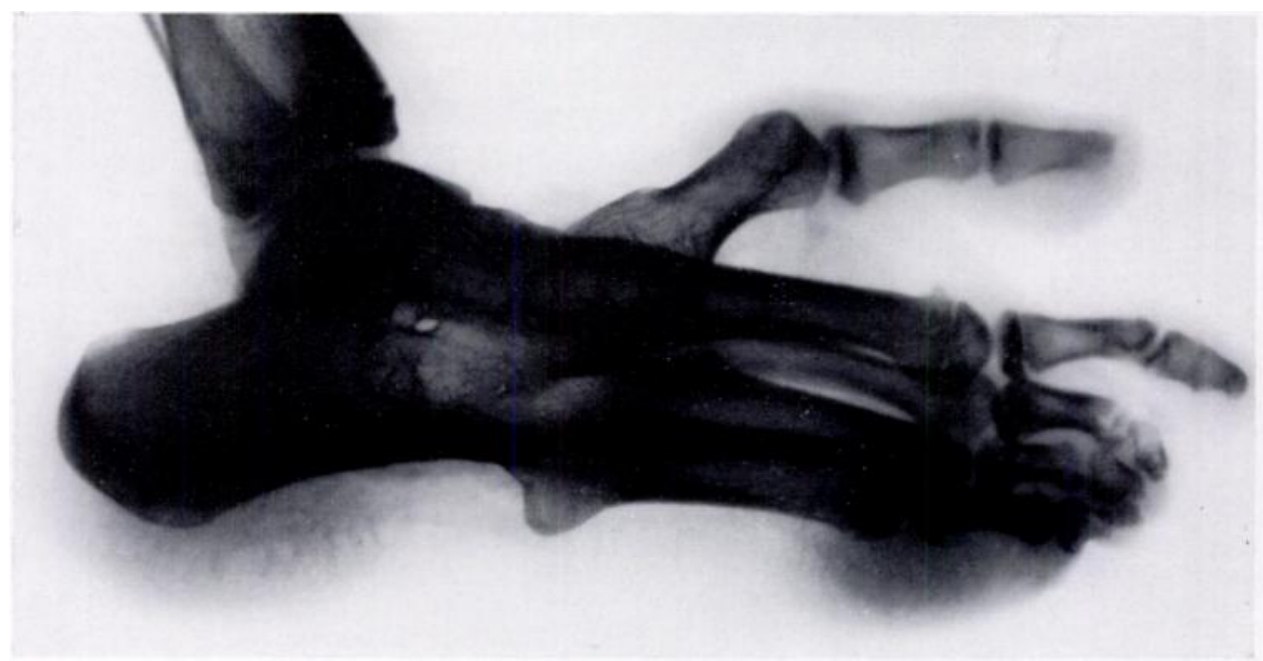

FIG. 12

Case 3-A lateral radiograph of the right foot showing extensive fusion of metatarsals and tarsus.

are more often involved, the scaphoid and lunate being seldom affected. The wrist joint usually retains good function. In the tarsus massive fusion is commonly seen; in extreme cases the whole tarsus is fused into a single block of bone. The tarso-metatarsal and intermetatarsal joints are also often involved. Such fusions result in the hands. It is of interest that tarsal fusion may be partly compensated for by the development of a "ball and socket" ankle joint. This is said to occur as a secondary process, a morphological response to altered function (Imhäuser 1970).

Congenital dislocation of the head of the radius 
TABLE I

Thirteen Reported Cases of the Nievergelt-Pearlman Syndrome

\begin{tabular}{|c|c|c|c|c|c|c|c|c|c|}
\hline $\begin{array}{c}\text { Case } \\
\text { number }\end{array}$ & Author & $\underset{\text { (years) }}{\text { Age }}$ & Sex & Symphalangism & $\begin{array}{l}\text { Carpal } \\
\text { fusion }\end{array}$ & $\begin{array}{l}\text { Tarsal } \\
\text { fusion }\end{array}$ & $\begin{array}{l}\text { Dislocation } \\
\text { of } \\
\text { radial head }\end{array}$ & $\begin{array}{l}\text { Humero-radial } \\
\text { or humero- } \\
\text { ulnar synostosis }\end{array}$ & $\begin{array}{c}\text { Impairment } \\
\text { of } \\
\text { hearing }\end{array}$ \\
\hline 1 & \multirow{2}{*}{ Pearlman et al. (1964) } & 33 & Female & + & + & + & + & - & - \\
\hline 2 & & 12 & Female & + & + & + & + & - & - \\
\hline 3 & \multirow{2}{*}{ Sano et al. (1964) } & 58 & Male & + & + & + & + & + & - \\
\hline 4 & & 18 & Male & + & + & + & + & - & - \\
\hline 5 & Shin et al. (1965) & 4 months & Male & + & + & + & - & + & - \\
\hline 6 & Dubois (1970) & 7 & Female & + & + & + & - & - & - \\
\hline 7 & \multirow{2}{*}{ Hasebe and Okochi (1972) } & 30 & Male & + & + & + & + & - & - \\
\hline 8 & & 6 & Female & + & + & + & - & $\vdots-$ & - \\
\hline 9 & \multirow{2}{*}{ Yasue et al. (1973) } & 30 & Male & + & - & - & i- & - & - \\
\hline 10 & & 4 & Female & + & + & $\therefore$ & - & 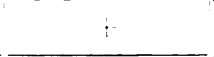 & - \\
\hline 11 & \multirow{3}{*}{ Murakami (1975) } & 48 & Male & + & + & + & 4 & - & $T$ \\
\hline 12 & & 15 & Female & + & + & + & + & - & 4 \\
\hline 13 & & 14 & Female & + & + & + & + & - & $\therefore$ \\
\hline
\end{tabular}

$$
+=\text { Present. } \quad-=\text { Absent }
$$

frequently occurs as a feature of the syndrome, anterior displacement being the commonest. The functional disability, if any, is minimal. Humero-radial or humeroulnar synostosis is found in some patients.

In addition to the several main features described above, in our cases there was conductive deafness, a finding not mentioned in previous reports. Vesell (1960), however, reported the occurrence of symphalangism and hearing loss in a mother and daughter. He ascribed the deafness to an abnormality in the ossicles of the middle ear and suggested the possibility of a single genetic defect producing both abnormalities. Strasburger, Hawkins,
Eldridge, Hargrave and McKusick (1965) made extensive studies of two large kindreds of symphalangism and pointed out that conductive deafness due to bony fusion of the stapes to the oval window occurred quite often. This led them to conclude that conductive deafness is an expression of the gene for symphalangism. They found that the onset of deafness was usually between the age of two and three and was progressive during childhood. Normal hearing had been restored in some patients by surgery. The clinical findings in our three patients also suggested that the loss of hearing was due to bony fusion of the ossicles of the middle ear.

\section{REFERENCES}

Dubois, H. J. (1970) Nievergelt-Pearlman syndrome. Journal of Bone and Joint Surgery, 52-B, 325-329.

Hasebe, K., and Okochi, I. (1972) Nievergelt's syndrome in a father and daughter. Tohoku Archivo por Ortopedia kaj Akcidenta Hirurgio, 15, 235-243. (In Japanese.)

Imhäuser, G. (1970) Kugelförmige Knöchelgelenke bei angeborenen Fusswurzelsynostosen. Zeitschrift für Orthopädie und ihre Grenzgebiete, 108, 247-258.

Nievergelt, K. (1944) Positiver Vaterschaftsnachweis auf Grund erblicher Missbildungen der Extremitäten. Archiv der Julius Klaus-Stiftung für Vererbungsforschung, Sozialanthropologie und Rassenhygiene, 19, 157-195.

Pearlman, H. S., Edkin, R. E., and Warren, R. F. (1964) Familial tarsal and carpal synostosis with radial-head subluxation (Nievergelt's syndrome). Journal of Bone and Joint Surgery, 46-A, 585-592.

Sano, S., Sakuma, T., Nakano, S., and Kurihara, T. (1964) Nievergelt syndrome in a father and son. The Journal of the Japanese Orthopaedic Association, 38, 819. (In Japanese.)

Shin, H., Ikuta, H., Hieda, H., and Ikari, T. (1965) A case of synostosis multiplex congenita. Orthopaedic Surgery, 16, 990-994. (In Japanese.)

Solonen, K. A., and Sulamaa, M. (1958) Nievergelt syndrome and its treatment. Annales Chirurgiae et Gynaecologiae Fenniae, $47,142-147$. Strasburger, A. K., Hawkins, M. R., Eldridge, R., Hargrave, R. L., and McKusick, V. A. (1965) Symphalangism: Genetic and clinical aspects. Bulletin of the Johns Hopkins Hospital, 117, 108-127.

Vesell, E. S. (1960) Symphalangism, strabismus and hearing loss in mother and daughter. New England Journal of Medicine, $263,839-842$.

Yasue, K., Fujii, H., Kumon, H., and Sakabe, Y. (1973) Case reports of Nievergelt-Pearlman syndrome. The Central Japan Journal of Orthopaedic and Traumatic Surgery, 16, 318-320. (In Japanese.) 